\title{
Optimization Design and Simulation for Pricking Mechanism of Off-Centre Embedded Seed Metering Device
}

\author{
Mutong $\mathrm{Li}^{1}$, Fujun Zhou ${ }^{1}$, Tianyu $\mathrm{Li}^{1} \&$ Yuan $\mathrm{Wei}^{1}$ \\ ${ }^{1}$ College of Engineering, Northeast Agricultural University, Harbin, China \\ Correspondence: Fujun Zhou, College of Engineering, Northeast Agricultural University, No. 59 Mucai Street, \\ Xiangfang District, Harbin, Heilongjiang Province, China. Tel: 86-451-5519-1280 E-mail: fjzhou@163.com
}

Received: March 22, 2017

Accepted: April 13, 2017 Online Published: May 15, 2017

doi:10.5539/jas.v9n6p221

URL: https://doi.org/10.5539/jas.v9n6p221

The research is financed by National Science and Technology Support Program 12th Five-Year 810056.

\begin{abstract}
In order to improve the quality of pricking hole and reduce throwing soil as merering the field, this paper presents a method of off-centre embedded pricking mechanism operation. Established a mathematical model of pricking hole mechanism, preparation of computer aided analysis platform by using VB software, and the simulation effects are buried and the effects of the eccentricity, rocker arm length, pricking hole connected with the handle, the swing rod length, length the pricking hole angle and swing arm and the connecting rod handle parameters related to the initial position. One group of optimization parameters: radial eccentricity $50 \mathrm{~mm}$, pricking hole arm length $220 \mathrm{~mm}$, connecting handle length $135 \mathrm{~mm}$, pendulum length $120 \mathrm{~mm}$, pricking hole arm and the connecting handle 55 degree angle, pendulum hinge rotation center end and rocker wire length 130 $\mathrm{mm}$, connecting with the horizontal angle of 5 degrees. Through the verification, pricking hole mechanism after optimization has been a significant improvement in reducing throwed soil problems and improve the pricking quality.
\end{abstract}

Keywords: seeder, pricking mechanism, parameter optimization, computer-aided analyzing, design

\section{Introduction}

At present, no-tillage planter was parted into mechanical and pneumatic according to the operation mode. Because ditching devices are assembled in the front of metering device in traditional tools. High resistance operation that sources from the interaction between ditching devices and soil will increase the traction energy consumption and equipment vibration (Yuexia, 2003), moreover, the metering pipeline of seed-outlet often clogs up with soil. These problems always affect the seeding quality, thus impediment the development of seed metering mechanism and the improvement of operation mode. This paper aimed at above problems and based on the principle of crank-rocker mechanism, put forward a type of pricking mechanism with off-centre embedded seed metering device operation mode (Fei et al., 2016; Hongxin, 2017; Jinwu et al., 2015). Optimize the pricking motion trace by using VB programming software. Furthermore, improve structure parameters and installation angle of pricking mechanism, and verify its applicability to overcome the main disadvantages of the traditional seed metering device, that within high resistance and large power, and solve the phenomenon of soil plugging.

\section{Mechanism Composition and Principle}

\subsection{Mechanism Composition}

Its working principle is: when it works, the power output connecting hole on the off-centre concave hole wheel is a power input, and the off-centre concave hole wheel driven by rotating principal axis eccentricity. Inside the off-centre concave hole wheel, embed a non-circular concave slideway. The return spring loaded in the piston chamber of pricking arm shell. Slideway and spring both drives the piston whose end loads in bearing to take linear recipro-cating motion in the piston chamber, which is in the pricking arm shell. At the same time, the off-centre concave hole wheel drives the pricking arm shell to take reciprocating rotation; when the pricking arm shell is rotated close to the ground, the piston out from the piston chamber into the soil and prick a hole under the function of the non-circular concave slideway. When the piston moves upward under the function of return spring which is compressed, seeds are thrown out from the seed metering chamber of the pricking arm to the 
piston chamber, and then they are thrown out from the connecting port at the lower end of the piston chamber to the hole. This is a continuous and integrated operation by prinking hole and seed metering. (Chinese Patent No. 201710007400.9, 201710007398)

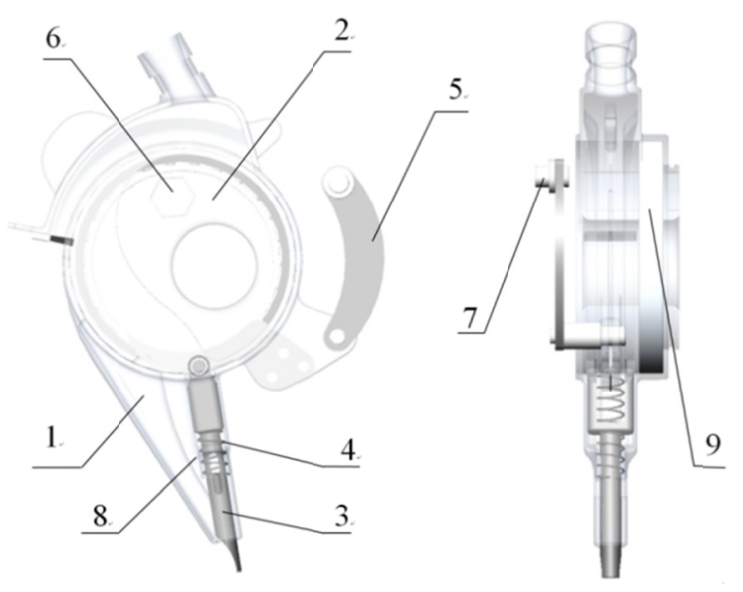

Figure 1.3D model of the off-centre embeded pricking hole metering mechanism

Note. 1. Pricking arm shell; 2. Off-centre concave hole wheel; 3. Piston; 4. Return spring; 5 . Swing rod; 6. Principal axis; 7. Mounting shaft; 8. Piston chamber; 9. Bearing.

Because the piston intalled inside the pricking arm shell, it only exist relative motion with pricking arm shell. This paper focuses on optimization design for composition parameters and penetrating trace of pricking mechanism. The motion principle skeleton of the mechanism is shown in Figure 2. It mainly consists of the rocker, the pricking arm, the connecting handle and the swing rod. The point $\mathrm{O}$ is the rocker rotation center, and equipped with coaxial on mounting rack. The point $\mathrm{C}$ is the hinge point between the end of the swing rod and mounting rack. The distance of Line $\mathrm{OC}$ is $\mathrm{L}_{4}$, and the angle between horizontal plane and OC is $\gamma$. The angle between the rocker and the connecting handle is $\delta$. The rocker and the connecting handle are hinged on the point A. The connecting handle and the swing rod are hinged on the point B. The point D is the prickly endpoint. When the pricking mechanism operates, the rocker takes circular motion around the point $\mathrm{O}$ and drives the pricking arm to swing periodically, thus cause the change of the trace of pricking cusp. By adjusting the parameters, we get the absolute motion trace that meets the working requirement of the pricking mechanism to achieve that the angle between the returned line of the pricking cusp and the entered line of the pricking cusp limited in $0^{\circ}-10^{\circ}$, accordingly, reduce the phenomenon of soil digging.

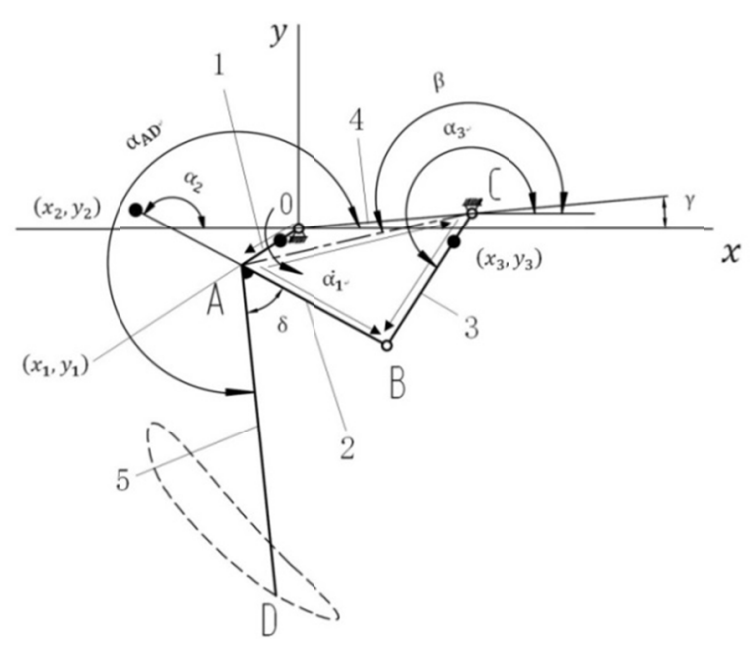

Figure 2. The principle skeleton of mechanism

Note. 1. Rocker; 2. Connecting handle; 3. Swing rod; 4. Fixed beam; 5. Pricking arm. 


\section{Establish Mathematical Mode}

Pricking mechanism kinematics analysis as shown in Figure 2, as known constant $\mathrm{L}_{1}, \mathrm{~L}_{2}, \mathrm{~L}_{3}, \mathrm{~L}_{10}, \mathrm{~L}_{2 \mathrm{~A}}, \mathrm{~L}_{3 \mathrm{C}}, \mathrm{x}_{\mathrm{C}}, \mathrm{y}_{\mathrm{C}}$, $\dot{\alpha}_{1}$, as known variables $\alpha_{1}$.

Establish vector equation of mechanism

$$
\overrightarrow{\mathrm{OA}}+\overrightarrow{\mathrm{OB}}=\overrightarrow{\mathrm{OC}}+\overrightarrow{\mathrm{CB}}
$$

Transform as analytic form:

$$
\begin{gathered}
\left\{\begin{array}{l}
\mathrm{x}_{\mathrm{A}}=\mathrm{L}_{1} \cos \alpha_{1} \\
\mathrm{y}_{\mathrm{A}}=\mathrm{L}_{1} \sin \alpha_{1}
\end{array}\right. \\
\left\{\begin{array}{c}
\mathrm{x}_{\mathrm{B}}=\mathrm{x}_{\mathrm{C}}+\mathrm{L}_{3} \cos \alpha_{3}=\mathrm{x}_{\mathrm{A}}+\mathrm{L}_{2} \cos \alpha_{2} \\
\mathrm{y}_{\mathrm{B}}=\mathrm{y}_{\mathrm{C}}+\mathrm{L}_{3} \sin \alpha_{3}=\mathrm{y}_{\mathrm{A}}+\mathrm{L}_{2} \sin \alpha_{2}
\end{array}\right.
\end{gathered}
$$

Simplify Equations (2):

$$
\left(\mathrm{x}_{\mathrm{C}}-\mathrm{x}_{\mathrm{A}}\right)^{2}+\left(\mathrm{y}_{\mathrm{C}}-\mathrm{y}_{\mathrm{A}}\right)^{2}-\mathrm{L}_{2}^{2}+\mathrm{L}_{3}^{3}+2 \mathrm{~L}_{3}\left[\left(\mathrm{x}_{\mathrm{C}}-\mathrm{x}_{\mathrm{A}}\right) \cos \alpha_{3}+\left(\mathrm{y}_{\mathrm{C}}-\mathrm{y}_{\mathrm{A}}\right) \sin \alpha_{3}\right]=0
$$

For formula:

$\mathrm{L}_{1}$ : The length of Rocker OA, mm; $\mathrm{L}_{2}$ : The length of connecting handle $\mathrm{AB}, \mathrm{mm} ; \mathrm{L}_{3}$ : The length of oscillationg bar BC, mm; $\alpha_{1}$ : The rotation angle of Rocker OA, $\left({ }^{\circ}\right) ; \alpha_{2}$ : The intersection angle of connecting handle $\mathrm{AB}$ and $\mathrm{x}$ axis, $\left({ }^{\circ}\right) ; \alpha_{3}$ : The intersection angle of oscillationg bar BC and level, $\left({ }^{\circ}\right) ; \dot{\alpha}_{1}$ : The palstance of Rocker $\mathrm{AB}, \mathrm{rad} / \mathrm{s}$.

Set the intersection angle between the $\mathrm{AC}$ line and the $\mathrm{x}$ axis as $\beta$, then.

$$
\tan \beta=\left(\mathrm{y}_{\mathrm{A}}-\mathrm{y}_{\mathrm{C}}\right) /\left(\mathrm{x}_{\mathrm{A}}-\mathrm{x}_{\mathrm{C}}\right)
$$

Simplify the two formulas above:

$$
\cos \left(\alpha_{3}-\beta\right)=\frac{\mathrm{L}_{3}^{3}+\left(\mathrm{x}_{\mathrm{A}}-\mathrm{x}_{\mathrm{C}}\right)^{2}+\left(\mathrm{y}_{\mathrm{A}}-\mathrm{y}_{\mathrm{C}}\right)^{2}-\mathrm{L}_{2}^{2}}{2 \mathrm{~L}_{3} \sqrt{\left(\mathrm{x}_{\mathrm{A}}-\mathrm{x}_{\mathrm{C}}\right)^{2}+\left(\mathrm{y}_{\mathrm{A}}-\mathrm{y}_{\mathrm{C}}\right)^{2}}}
$$

As $\alpha_{3}-\beta$ is an inner angle of $\triangle \mathrm{ABC}, \alpha_{3}-\beta$ belongs to $0 \sim \pi$ (Yun, 2005). Thus $\alpha_{3}$ can be figure out.

OA rod centroid coordinate:

$$
\left\{\begin{array}{l}
\mathrm{x}_{1}=\mathrm{L}_{10} \cos \alpha_{1} \\
\mathrm{y}_{1}=\mathrm{L}_{10} \sin \alpha_{1}
\end{array}\right.
$$

The coordinate of $\mathrm{AB}$ rod centroid:

$$
\left\{\begin{array}{l}
\mathrm{x}_{2}=\mathrm{x}_{\mathrm{A}}+\mathrm{L}_{2 \mathrm{~A}} \cos \alpha_{2} \\
\mathrm{y}_{2}=\mathrm{y}_{\mathrm{A}}+\mathrm{L}_{2 \mathrm{~A}} \sin \alpha_{2}
\end{array}\right.
$$

From the formula above:

$$
\tan \alpha_{2}=\left(\mathrm{y}_{\mathrm{B}}-\mathrm{y}_{\mathrm{A}}\right) /\left(\mathrm{x}_{\mathrm{B}}-\mathrm{x}_{\mathrm{A}}\right)
$$

The coordinate of $\mathrm{BC}$ rod centroid:

$$
\left\{\begin{array}{l}
x_{3}=x_{C}+L_{3 C} \cos \alpha_{3} \\
y_{3}=y_{C}+L_{3 C} \sin \alpha_{3}
\end{array}\right.
$$

For formula:

$\mathrm{L}_{10}$ : The distance from $\mathrm{OA}$ centroid to $\mathrm{O}, \mathrm{mm} ; \mathrm{L}_{2 \mathrm{~A}}$ : The distance from $\mathrm{AB}$ centroid to $\mathrm{A}, \mathrm{mm} ; \mathrm{L}_{3 \mathrm{C}}$ : The distance from $\mathrm{BC}$ centroid to $\mathrm{C}, \mathrm{mm}$.

\subsection{The Displacement Equation of Pricking Cusp}

Relative motion displacement of pricking cusp D:

$$
\left\{\begin{array}{l}
\mathrm{x}_{\mathrm{D}}=\mathrm{x}_{\mathrm{A}}+\mathrm{L}_{\mathrm{AD}} \cos \left(\alpha_{2}+\alpha_{\mathrm{AD}}\right) \\
\mathrm{y}_{\mathrm{D}}=\mathrm{y}_{\mathrm{A}}+\mathrm{L}_{\mathrm{AD}} \sin \left(\alpha_{2}+\alpha_{\mathrm{AD}}\right)
\end{array}\right.
$$

For formula:

$\mathrm{L}_{\mathrm{AD}}$ : The length of pricking limb $\mathrm{AD}, \mathrm{mm} ; \alpha_{2}$ : The angle between connecting handle $\mathrm{AB}$ and $\mathrm{x}$ axis, $\left({ }^{\circ}\right) ; \alpha_{\mathrm{AD}}$ : The angle between pricking limb $\mathrm{AD}$ and $\mathrm{x}$ axis, $\left({ }^{\circ}\right)$. 
Absolute motion displacement of pricking cusp D:

For formula: $\mathrm{H}$ : Corn spacing in rows, $\mathrm{mm}$

$$
\left\{\begin{array}{c}
\mathrm{x}_{\mathrm{D}^{\prime}}=\mathrm{x}_{\mathrm{D}}-\alpha_{1} \mathrm{H} / 360 \\
\mathrm{y}_{\mathrm{D}^{\prime}}=\mathrm{y}_{\mathrm{D}}
\end{array}\right.
$$

\subsection{The Velocity Equation of Pricking Cusp}

If the pricking hole mechanism possess horizontal forward speed $\mathrm{v}_{1}=0$, the relative velocity equation of the pricking cusp D would be:

$$
\left\{\begin{array}{l}
\mathrm{x}_{\mathrm{D}}=\dot{\mathrm{x}}_{\mathrm{A}}-\left(\dot{\alpha}_{2}+\alpha_{\mathrm{AD}}\right) \mathrm{L}_{\mathrm{AD}} \sin \left(\alpha_{2}+\alpha_{\mathrm{AD}}\right) \\
\dot{\mathrm{y}_{\mathrm{D}}}=\dot{\mathrm{y}}_{\mathrm{A}}+\left(\dot{\alpha}_{2}+\dot{\alpha}_{\mathrm{AD}}\right) \mathrm{L}_{\mathrm{AD}} \cos \left(\alpha_{2}+\alpha_{\mathrm{AD}}\right)
\end{array}\right.
$$

If the pricking hole mechanism possess horizontal forward speed $\mathrm{v}_{1} \neq 0$, the absolute velocity equation of the pricking cusp D would be:

\section{Parameter Optimization}

$$
\left\{\begin{array}{c}
\mathrm{x}_{\mathrm{D}^{\prime}}=\dot{\mathrm{x}_{\mathrm{D}}}-\mathrm{v}_{1} \frac{\alpha_{1}}{\dot{\alpha}_{1}} \\
\dot{\mathrm{y}_{\mathrm{D}^{\prime}}}=\dot{\mathrm{y}_{\mathrm{D}}}
\end{array}\right.
$$

In this paper, by using VB software, writing a program optimizes the structure parameters of the pricking hole mechanism. Depend on the scale method, the coordinate is transformed into cartesian coordinates that is convenient to actualize the programming (Xiaohuan et al., 2011; Chunxiang et al., 2016). The program is mainly uesd to optimize the structure parameters of pricking hole mechanism. The settings interface of parameter directly placed on the right side can be conveniently debugging each parameter value. Meanwhile, in the main interface, all kind of traces which is related with pricking arm cusp can be observed and the reliability of various data also can be analysised.

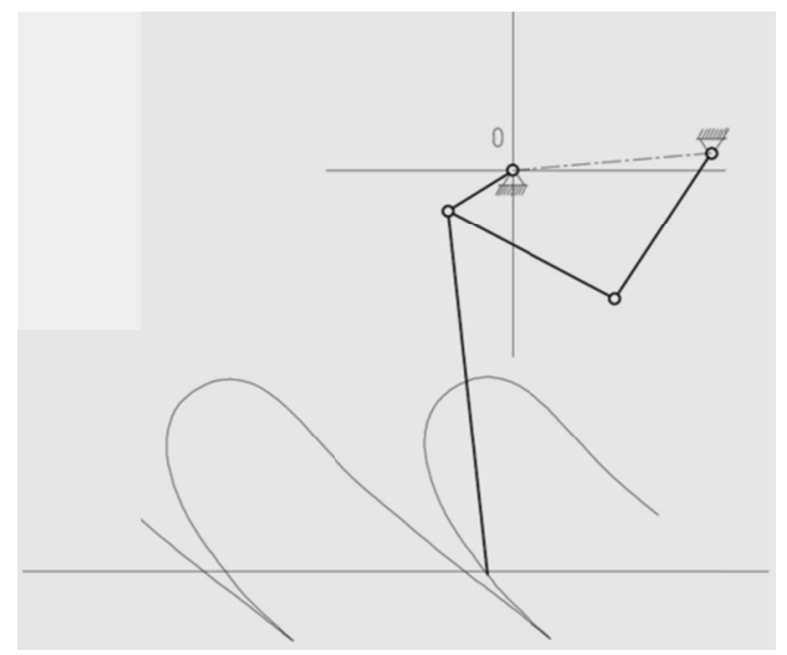

Figure 3. Absolute motion trace of pricking mechanism

In order to impel the pricking hole into soil smoothly, and without holding and lifting up soil, the trace of pricking cusp should fulfil: (1) Pricking hole into soil with zero speed, the angle between the returned line of the pricking cusp and the entered line of the pricking cusp is less than $10^{\circ}$. (2) The trace of hole is limited to the range of 12 20 mm (Jinfeng et al., 2010). (3) The depth of hole is limited to the range of 30 50 mm. (4) The hole distance is limited to the range of $200 \sim 300 \mathrm{~mm}$. In order to enhance the quality of pricking hole and improve the dynamic characteristics of pricking hole mechanism, set the target of optimization parameters: $\mathrm{L}_{1}$, $\mathrm{L}_{2}, \mathrm{~L}_{3}, \mathrm{~L}_{4}, \mathrm{~L}_{5}, \gamma, \delta$ and so on. By adjusting the parameter values, the trace of pricking arm cusp can be dynamically adjusted. Using real-time coordinate positioning methods selected the optimal trace to satisfy the conditions above as shown in Figure 3. For the value of the parameters: $\mathrm{L}_{1}=50 \mathrm{~mm}, \mathrm{~L}_{2}=135 \mathrm{~mm}, \mathrm{~L}_{3}=120 \mathrm{~mm}$, $\mathrm{L}_{4}=130 \mathrm{~mm}, \mathrm{~L}_{5}=220 \mathrm{~mm}, \gamma=5^{\circ}, \delta=55^{\circ}$. With the optimal results, the angle between pricking cusp and the 
horizontal plane is limited to $65^{\circ} \sim 75^{\circ}$ when pricking into soli, the depth of pricking hole is $44.6 \mathrm{~mm}$, the lengthwise length of hole is $13.8 \mathrm{~mm}$, the hole distance is $245 \mathrm{~mm}$, satisfy the design requirements.

\section{Velocity Analysis}

On the basis of the optimal parameters of the VB program, draw the 3D model perfectly. According to the simulation of Adams which is a kind of dynamic analysis software, the relative velocity simulation curve of pricking arm cusp D can be obtained, as shown in Figures 4 and 5.

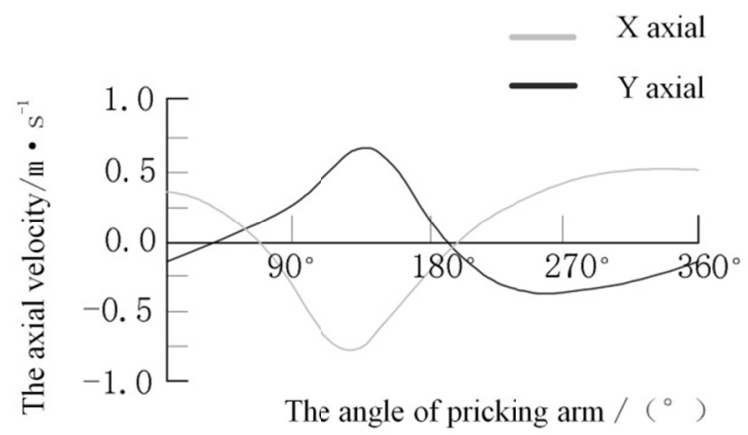

Figure 4. The axial velocity curve of the $\mathrm{D}$ point at the cusp of pricking arm for relative motion

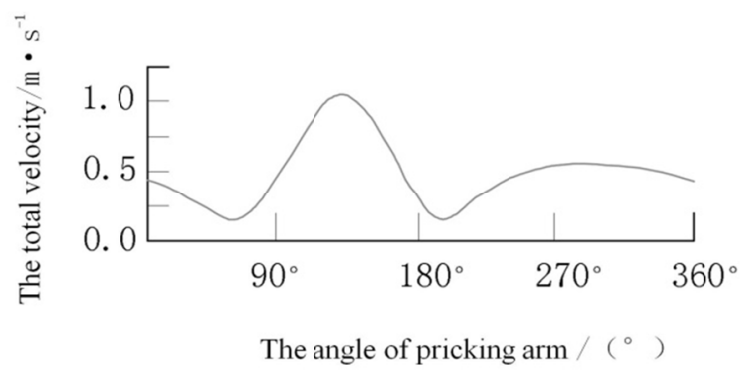

Figure 5. The total velocity curve of the D point at the cusp of pricking arm for relative motion

As shown in Figure 3, analysis the D point speed curve from $\mathrm{X}$ direction, when the rocker arm angle is rolled to the range of $70^{\circ} \sim 190^{\circ}$, the pricking hole mechanism is in the return process. Analysis the D point speed curve from Y direction, when the pricking cusp is divorced from soil, the pricking arm owns biggish speed so that the lifting action can be rapidly completed; when the rocker arm angle is greater than $190^{\circ}$, the mechanism gets into the process of pricking hole; when the rocker arm angle is about $250^{\circ}$, the pricking hole mechanism is closed to the ground. According to Figure 5, the maximum speed of the pricking arm cusp D is up to $0.52 \mathrm{~m} / \mathrm{s}$, which can ensure a perfect effect to prick into soil. As shown in Figure 4, when the rocker arm angle is limited in the range of $\left[280^{\circ}, 360^{\circ}\right]$ and $\left[0^{\circ}, 35^{\circ}\right]$, the motion of pricking arm cusp is in soil, which is metering process. As shown in Figure 5, the motional velocity of pricking cusp is gentle and decreasing, which is conducive to improve the stability of metering in the hole and to reduce the soil disturbance. It satisfies the design requirements.

\section{Conclusions}

Put forward a kind of off-centre embedded type crank rocker motion principle of pricking hole seeding operation mode. through the establishment of mathematical model and using VB software platform for dynamic simulation (Chuanyu et al., 2008; Ge et al., 2000), determine the pricking hole mechanism parameters: rocke is $50 \mathrm{~mm}$, connecting handle is $135 \mathrm{~mm}$, swing rod is $120 \mathrm{~mm}$, fixed beam is $140 \mathrm{~mm}$, pricking arm is $220 \mathrm{~mm}$, the angle between horizontal plane and fixed beam is $5^{\circ}$, the angle between the rocker and the connecting handle is $55^{\circ}$. We get the speed variation of $\mathrm{D}$ point by relative motion simulation of 3D model based on Adams software, and analyzes the adaptability of pricking capability and metering performance. Verify the optimized parameters of pricking arm cusp that the return trace and unearthed penetrating trace is less than $10^{\circ}$. Meet the requirements that reducing the phenomenon of soil disturbance. Furthermore, lay the theoretical foundation for the further design of metering mechanism. 


\section{Acknowledgements}

First of all, thank you for the guidance of Professor Fujun Zhou and the funds of National Science and technology support program 12th Five-Year. Secondly, thanks to the help from Li Tianyu and Wei Yuan during the design translation process. Third, thanks to editors and experts of the journal with valuable views and suggestions. Therefore, with the basis above the manuscript could be further improved.

\section{References}

Anantachar, M., Prasanna, G., Kumar, V., \& Guruswamy, T. (2010). Neural network prediction of performance parameters of an inclined plate seed metering device and its reverse mapping for the determination of optimum design and operational parameters. Computers and Electronics in Agriculture, 72, 87-98.

Barut, Z. B., \& Ozmerzi, A. (2004). Effect of Different Operating Parameters on Seed Holding in the Single SeedMetering Unit of a Pneumatic Planter. Turkish Journal of Agriculture \& Forestry, 6, 435-441.

Chuanyu, W., Yun, Z., \& Jianneng, C. (2008). Rice transplanter transplantingmechanism visual optimization design of human-computer interaction. Transactions of the Chinese Society for Agricultural Machinery, $39(1), 46-49$.

Chunxiang, L., Jinwu, W., Han, T., Wenqi, Z., Qi, W., \& Wenpan, Y. (2016). Dynamics Analysis and Test on Picking Hole Mechanism of Liquid Fertilizer Based on Bezier Curve. Transactions of the Chinese Society for Agricultural Machinery, 47(5), 115-122. https://doi.org/10.6041/j.issn.1000-1298.2016.05.016

Fei, D., Wuyun, Z., Linrong, S., Xuepeng, T., Jiuxin, W., \& Xiaolong, L. (2016). Design and Experiment of Hill-seeder with Whole Plastic-film Mulching on Double Ridges for Corn Based on Mechanism with Approximate Constant Speed. Transactions of the Chinese Society for Agricultural Machinery, 47(11), 74-81. https://doi.org/10.6041/j.issn.1000-1298.2016.11.010

Ge, L., Yun, Z., \& Gaohong, Y. (2000). Theoretical Analysis and Parameters Optimizing of Separating Planting Mechanism with Planetary Elliptic Gears. Transactions of the Chinese Society of Agricultural Engineering, 16(4), 78-81.

Hongxin, L. (2007). Experimental study on optimizing structural parameters of 2B-JP-FL01 seed-metering device. Transactions of the Chinese Society of Agricultural Engineering, 23(9), 106-110.

Jinfeng, W., Jinwu, W., Yiyuan, G., Yahua, L., \& Jinyan, J. (2010). Design on Pricking Hole Mechanism of Deep-fertilization Liquid Fertilizer Applicator. Transactions of the Chinese Society for Agricultural Machinery, 41(4), 52-55. https://doi.org/10.3969/j.issn.1000-1298.2010.04.011

Jinwu, W., Han, T., Wenqi, Z., Wenpan, Y., \& Qi, W. (2015). Improved Design and Experiment on Pickup Finger Precision Seed Metering Device. Transactions of the Chinese Society for Agricultural Machinery, 46(9), 68-76. https://doi.org/10.6041/j.issn.1000-1298.2015.09.010

Mutong, L., Xiangyu, W., \& Fujun, Z. (2016). Working Parameters Optimization and Experiment of Precision Hole Fertilization Control Mechanism for Intertilled Crop. Transactions of the Chinese Society for Agricultural Machinery, 47(9), 37-43. https://doi.org/10.6041/j.issn.1000-1298.2016.09.006

Raji, A. O., \& Favier, J. F. (2004). Model for the deformation in agricultural and food particulate materials under bulk compressive loading using discrete element method. II. Compression of oilseeds. Journal of Food Engineering, 64(3), 373-380.

Singh, D. C., Singh, G., \& Saraswat, D. C. (2004). Optimisation of Design and Operational Parameters of a Pneumatic Seed Metering Device for planting Cottonseeds. Biosystems Engnineering, 92(4), 429-438.

Xiaohuan, X., Jinwu, W., Chunling, L., \& Chengliang, Z. (2011). Optimal Design and Simulation on Pricking Hole Mechanism of Liquid Fertilizer Applicator. Transactions of the Chinese Society for Agricultural Machinery, 42(2), 80-83. https://doi.org/10.3969/j.issn.1000-1298

Yuexia, Z. (2003). The key technology of mechanical precision seed-metering device. Nanjing Agricultural University.

Yun, Z. (2005). Numerical analysis and synthesis of mechanism. Mechanical Industry Press. 


\section{Appendix}

Appendix A. The parameter optimization platform based on Visual Basic (Chinese button)



Appendix B. Dynamic simulation and its trajectory by ADAMS

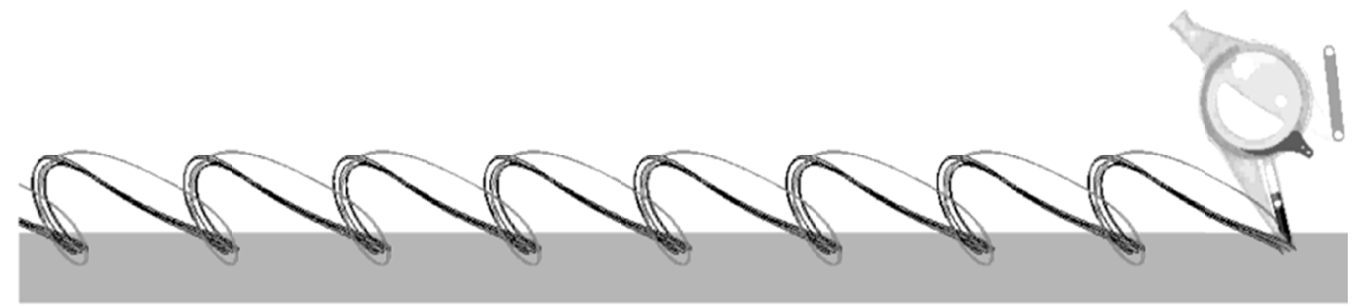

Appendix C. Velocity analysis gragh of by ADAMS

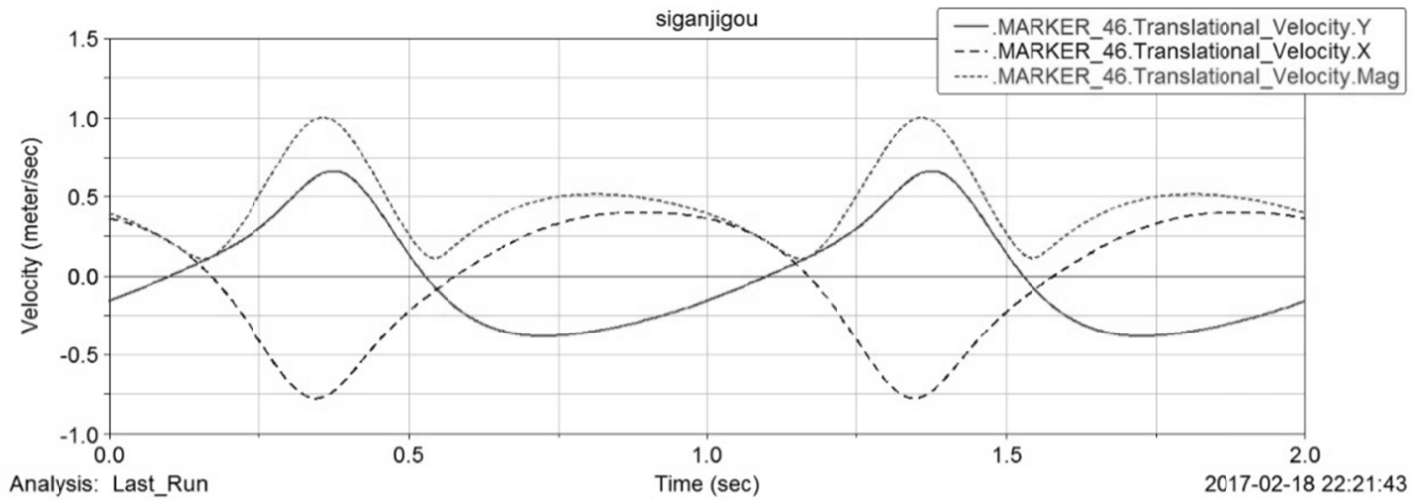




\section{Copyrights}

Copyright for this article is retained by the author(s), with first publication rights granted to the journal.

This is an open-access article distributed under the terms and conditions of the Creative Commons Attribution license (http://creativecommons.org/licenses/by/4.0/). 